\section{Programs to solve problems}

\author{
S.W.D. Steel
}

Journal of Automated Reasoning. Editorin-chief L. Wos. Reidel. 4/yr. Dfl. 233, \$97 (institutional); Dfl.100, $\$ 39$ (individual).

Automated reasoning, states the Information for Authors of this new journal, is "a field whose objective is the design and implementation of a computer program that serves as an assistant in solving problems and in answering questions that require reasoning". That seems a natural and important constituency, and the papers so far published come from it.

The field is, of course, a continuum of subjects from the theoretical to the practical, and the journal reflects this. There are highly formal contributions on such topics as unification and intelligent backtracking that are important in actual programs throughout automated reasoning, and also papers about programs intended to solve particular problems (in planning, scheduling and expert systems, for example) which pay particular attention to theory to show why the inferences made are the right ones. The extrema, pure mathematical logic and pure program de-

COMPLETE
YOUR NUCLEAR
LIBRARY WITH . .
Continuing the
Nuclear Dialogue
Selected Essays
by
ALVIN M. WEINBERG
and
Nuclear Criticality Safety
by
RONALD A. KNIEF
order today
from the
American Nuclear Society
La Grange Park, IL 60525
(312) 352-6611

Reader Service No.10 tails, are rightly missing, though from the evidence of later issues there is the danger that formal papers might come to overwhelm contributions dealing with systems and algorithms. That would be a pity. As far as I can judge, the material published to date has been both substantial and interesting.

Authors are allowed sufficient space to explain the interest of their work and relate it to that of others (though not all of them do so). They can thus both present new research to specialists and introduce established work to those in other areas of artificial intelligence and computer science; with the paucity of intermediateand higher-level textbooks on the subject, this is a valuable feature. For the same reason, the "Problem Corner" for passing on automated reasoning folklore is a good idea.

Given the level of interest in the field, artificial intelligence has not spawned as many journals as one might have expected

\section{Nervous behaviour}

\section{Peter Bryant}

Developmental Neuropsychology. Editor Francis J. Pirozzolo. Lawrence Erlbaum. 4/yr. North America $\$ 65$ (institutional), $\$ 25$ (individual); elsewhere $\$ 74$ (institutional), \$34 (individual).

THF main concern of developmental psychology is change. The behaviour of young children, and of old people too, changes rapidly and often quite dramatically over time, and these changes must be related in some way to changes in the central nervous system. In fact many of the neurological developments that take place with age are very well documented, but their exact relationship to the development of behaviour remains a mystery.

The subject is a difficult one for a number of reasons, but one barrier has been the lack of a suitable forum for discussion. Papers on the subject tend to end up in journals of developmental psychology, which are not read much by neuropsychologists, or in specialist journals of neurology or neuropsychology. One journal, $D e-$ velopmental Medicine and Child Neurolo$g y$, has been remarkably successful and does cross this boundary, but it has concentrated on clinical topics. This new journal, Developmental Neuropsychology, spreads its net more widely, covering normal as well as abnormal development.

Much of the information that we do have on the possible relations between neurological and behavioural development comes in one of two forms. One is work on the specialization of the two cerebral hemispheres and the other is information about groups of children who have and some that do exist have consisted of little more than advertising. Instead there has been heavy reliance on the proceedings of a few highly regarded conferences and on the flagship journal Artificial Intelligence. These, as well as books about particular systems, could provide some competition for the new journal, but it is subsumed by none of them. It is clear there is enough good work to fill another journal; conference articles are too short to be expository; and books are for those who already know what they need.

My single reservation is about the poor proof-reading. Only errors in the prose actually strike one, but they give rise to doubts about the accuracy of the symbolic passages. That apart, Journal of Automated Reasoning is a much-needed publication that has made an auspicious start.

S.W.D. Steel is a Lecturer in the Department of Computer Science, University of Essex, Colchester CO4 $3 S Q, U K$.

specific difficulties, such as problems with reading, which might be due to some malfunction in the central nervous system. The predominance of these two sources of information is clearly reflected in the articles in this new journal. Several deal with the different functions of the left and right hemispheres and the possibility that the relations between them might change with age. Many of the remaining papers are about problem groups of children. The opening article is about dyslexia, and others deal with learning difficulties of one sort or another. There are as well papers which do not fall into these two categories. Several deal with old age, and there are some worthy, though speculative, attempts to relate developnıental changes in behaviour to neuroanatomical changes.

By and large the standard is high, though there are lapses. It ought to be editorial policy by now to be wary of experiments which simply compare groups of backward and normal readers whose age is the same and who thus have different reading levels. The trouble, now widely recognized, with this sort of comparison is that it cannot distinguish cause from effect. A difference between the two groups could as well be the result of their backwardness. Yet results of this type are reported in the journal without any mention of their inherent weakness.

In general, though, the journal is competent and interesting. It provides a useful extension to the platform already built by Developmental Medicine and Child Neurology, and it deserves the attention of psychologists and neurologists alike. $\square$

Peter Bryant is Watts Professor in the Department of Experimental Psychology, University of Oxford, South Parks Road, Oxford OXI 3UD, $U K$. 